\title{
Public Perception on Calligraphic Woodcarving Ornamentations of Mosques; a Comparison between East Coast and Southwest of Peninsula Malaysia
}

\author{
Ahmadreza Saberi ${ }^{1}$; Esmawee Hj Endut ${ }^{1}$; Sabarinah Sh Ahmad ${ }^{1}$; Shervin Motamedi ${ }^{2,3}$; Shahab \\ Kariminia $^{4}$; Roslan Hashim ${ }^{2,3}$ \\ ${ }^{1}$ Faculty of Architecture, Planning and Surveying, Universiti Teknologi MARA, Shah Alam, 40450, Malaysia \\ Email: $\underline{\text { saberi.ahmadreza@gmail.com }}$ \\ ${ }^{2}$ Department of Civil Engineering, Faculty of Engineering, University of Malaya, 50603, Kuala Lumpur, Malaysia \\ ${ }^{3}$ Institute of Ocean and Earth Sciences (IOES), University of Malaya, 50603, Kuala Lumpur, Malaysia \\ ${ }^{4}$ Department of Architecture, Faculty of Art, Architecture and Urban Planning, Najafabad Branch, Islamic Azad University, \\ Najafabad, Isfahan, Iran
}

\begin{abstract}
Woodcarving ornamentation is considered as, a national heritage and can be found in many Malaysian mosques. Woodcarvings are mostly displayed in three different motifs, namely floral, geometry and calligraphy. The application of floral and geometry motifs is to convey an abstract meaning of Islamic teachings to the viewers. However, the calligraphic decorations directly express the messages of Allah almighty or the sayings of the prophets to the congregations. Muslims are the main users of mosques as these are places for prayers as well as other religious and community activities. Therefore, the assessment of users' opinion about this type of decoration needs to be investigated. This paper aims to evaluate the perception of two groups of mosque users on the calligraphic woodcarving ornamentations from two regions, namely the East Coast and Southwest of Peninsula Malaysia. As Arabic is not the primary language in Malaysia, it would be interesting to find out how much of the calligraphic ornamentation is recognised and understood by the mosque users. The quantitative approach and questionnaire survey were adopted to fulfil the objectives of the study through convenient sampling where 420 questionnaire surveys were distributed at eight selected mosques. A total of 408 respondents amongst users completed and returned the survey forms. The mosques were chosen based on the abundance and diversity of calligraphy woodcarving elements found in the prayer hall. The Mann-Whitney U-test was conducted to find out the differences between the two groups of respondents. Ability of reading and understanding the Arabic scripts, the aesthetic values, the function, appropriate location and finally the desirability of scripts were assessed and compared between the participants of North East and Southwest of Peninsula Malaysia. The results showed that respondents of two areas in Malaysia had different opinions about this traditional sacred ornamentation in mosques. However, there were also similar ideas regarding to the items of variables between two evaluated groups of the study.
\end{abstract}

KeyWords: Mosque Ornamentation, Public Perception, Calligraphic Woodcarving, Malaysia 


\section{Introduction}

The arrival of Islam into Malay Peninsular took place in the early $14^{\text {th }}$ century. Islam was introduced to the indigenous Malay people through the Arab merchants who came to Melaka port for trading in the early $15^{\text {th }}$ century (Nasir, 1987). Within a few years, the multitude of mosques with varied architectural styles were built (Henderson, 2003). The decoration of mosques was not an issue in the early years. As time passed, these sacred buildings were ornamented through different decorative elements including vernacular and expatriated motifs. The floral patterns had been used in Malay architecture even before Islam (Kamarudin \& Said, 2009). However, foreign cultures introduced other types of motifs including calligraphy and geometry to the Malay craftsmen who soon became experts (Utaberta, Sojak, Surat, CheAni, \& Tahir, 2012). The local Muslims accepted the new decorative elements and particularly the calligraphy. The religious inscriptions as decorative elements were in the main concern of Muslims since they convey the messages of Quran and the Prophet Muhammad.

The purpose of this study is to compare the perception of mosque users from two regions (Southwest and East Coast of peninsula Malaysia) regarding Islamic inscriptions, which are mainly used as a decorative element in Malaysian mosques. The assessed factors included subjective aspects of calligraphic ornamentations such as the function and location of these sacred ornamentations. Meanwhile, public interests regarding to the legibility, aesthetic and preference of different types of scripts, which are mainly used in decorative inscriptions were examined. Thuluth, Kufi, Naskh, Nastaliq and Diwani are five common decorative scripts, not only in Malaysia, but also in many other Islamic countries.

Moreover, the scope of study covered two important regions in Malaysia, which have their own Islamic background and history. The researcher selected Melaka as one of the study area because Muslims Arab traders started to spread Islam from this region of Malaysia. The other selected region is Terengganu and Kelantan states in East Coast of Malaysia. The reason for choosing East Coast would be the ancient inscribed stone, which was found in the Tarsat River at Kuala Brang, Terengganu (Fig 1). The inscriptions on the stone are about Islamic Law and Malay kingdom and it was dated 4 Rejab 702 Hijri equal to 22 February of 1303, about 100 years before Islam came to Melaka. The stone is a valid evidence of arrival of Islam to these areas (Ahmad \& Resad, 2015; Utaberta et al., 2012).

\section{Ornamental Scripts in Architecture}

The Umayyad caliphs started to apply calligraphy in architectural decoration (Hillenbrand, 1999). Further, Hillenbrand also stated that the magnificent time for calligraphic art was between $11^{\text {th }}$ and $12^{\text {th }}$ centuries, when beautiful epigraphic inspirations in the Islamic lands emerged. Subsequently, creative designers developed novel styles of writing to demonstrate sacred Quranic massages through varieties of scripts.

\subsection{Common Ornamental Scripts}

Despite the variety of Arabic calligraphy, only a few of them are suitable to be implemented in architectural ornamentations (Etikan, 2008). The most common Arabic architectural scripts are shown in figure 2. Kufi had been one of the primary applied scripts in architectural decoration during the early Islamic time. The squared Kufi was the main focus of architectural decoration through reliefs on bricks applied on building façades. Etikan (2008) also noted that the Kufi script is undoubtedly the result of a designers' aspiration to innovate to respond to the need for religious decorative forms in the Islamic sacred art. Although Kufi script shows disordered proportion of vertical and horizontal characters, the overall features of the script is completely eye-catching. 


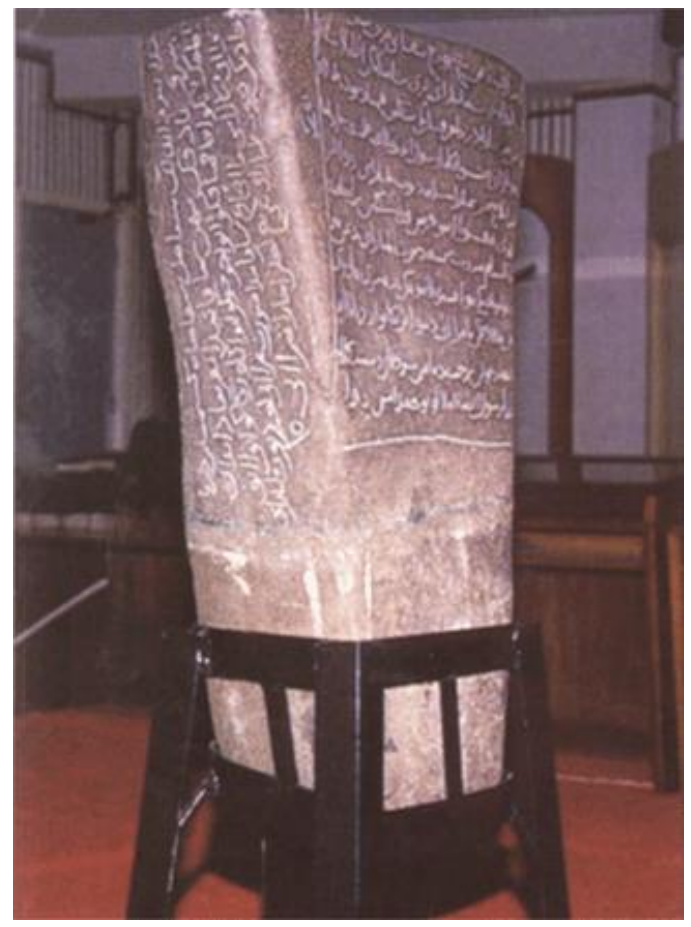

Fig. 1 The inscription stone found in Terengganu (Ahmad \& Resad, 2015)

The Kufi and other scripts originated from Kufi can be related to the group of angular scripts, while the other Arabic scripts which are demonstrated in the above figure are belonged to the cursive group of scripts (Blair, 2006). The origin of curved scripts is from the early decades of the Islamic developments since the roots of composition and scripts' feature came from pre-Islam era (Hillenbrand, 1999). The most frequent architectural cursive scripts are Thuluth, Nastaliq, Naskh and Diwani.

One of the popular scripts among calligraphers is Thuluth style. It is one of the primary cursive scripts, created in the $7^{\text {th }}$ century (Suleiman, 1999). Thulth is prominent for its stylish flexibility, which gives a remarkable complexity to this writing style. Professional calligraphers believe that the Thulth script is the optimum and artistic type of script to be used as architectural ornamentation (Suleiman, 1999; Turgut, 2014). Naskh as one of the cursive scripts was designed to make the readability of the Quran easy for Muslims (George, 2010). Although Naskh was mainly used to write the Quran, many designers observed it suitable as decorative element in mosques. Nastaliq has a rather new background compared with the other cursive scripts. This writing style originated from three former scripts namely Tawqi, Riqa and Taliq. The scripts were launched from Iranian calligraphers that altered the very rounded forms, mixed them into the characteristics of the Riqa script and overstated horizontal strokes of Taliq alphabets. Then the new ornamented writing style was created (Suleiman, 1999). However, it must be noted that Nastaliq script has not been commonly applied in woodcarving decorative elements since the way of pen movements is more suitable for ceramic decoration. Diwani script is another writing style which has been innovated by the Ottomans in Turkey. It was named as the Diwani script since it was used in the Ottoman Diwan (government). The readability of this writing style is intricate and people in the Turkish government used it as the secret writing style which the public could not read (Osborn, 2009). Diwani has been implemented as an ornamental element in architecture mainly in Middle East countries. 


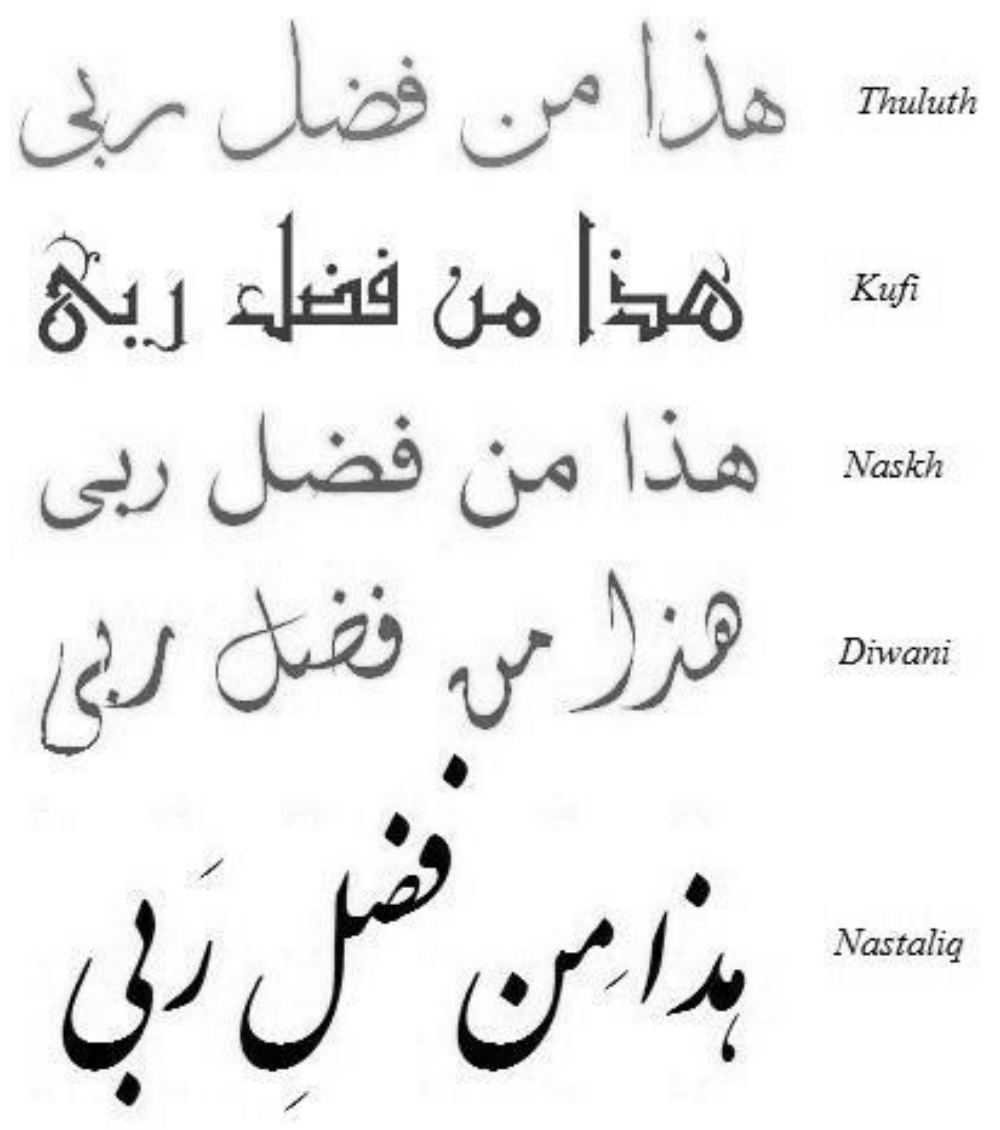

Fig. 2 The five most common ornamental scripts

\section{Public Perception}

The word "public perception" has been widely used in academic research from early $20^{\text {th }}$ century. The definitions stresses on the aspect of participation of public as a main element in the procedure of assessments (Shahedi, Keumala, \& Yaacob, 2012). Majority of social scientists determine public perception to be a reasonable invention of democracy in a society (Shahedi et al., 2012). Ahn (2007) claimed that there are various factors which affect assessments of public. The geographical factors have their own influence on our perception since different environments make different point of view. The cultural varieties in different parts of countries or even gender differences create a diversity of opinion regarding to subjects including architectural decorations (Najafi \& Kamal, 2012; Saberi, Endut, Ahmad, Motamedi, Kariminia, 2015; Agha, 2015).

\subsection{Public Perception and Mosques' Ornamentations}

Mazumdar and Mazumdar (2004) defined places as a physical location shaped by the connection of people with their environments, activities and purposes. The buildings have varied functions. There are places that the public relates to for religious or sacred ceremonies. They are constructed to cultivate human philosophies, beliefs and also improve human spirituality. Consequently, sacred architecture plays a role as the setting where one feels closer to God. Synagogue, churches, mosques and temples are samples of sacred buildings built for worship of God or other religious activities. These types of building should be magnificent for people and attract them to enter. So, decorations in the inside and outside of 
prayer rooms can be considered as a must (Saberi, et.al, 2015). Hence, calligraphers as designers of mosques decorations should appreciate and respect users' desires and consideration.

\subsection{Ability of Reading and Understanding of Arabic Scripts in Malaysia}

In Malaysia, the first language is Bahasa Malaya which is the official language of the country. Although the Malaysian Indian and Chinese use English as the second language in the country, Arabic language as the language of Islam is appreciated by the Muslims who mostly come from Malay background. Since the Muslim Holy book "Al-Qur'an" was revealed in Arabic language, there is no other way to improve Islamic knowledge except through enhancing the ability of reading and understanding the Arabic language. Therefore, the significance of Arabic language is undeniable, especially when the majority of religious scripts are written in this language. The Malaysian Muslims therefore, need to learn the language to expand their understanding of Islam (Kostof, 1995). Nevertheless, for majority of the public who want to appreciate the Quran, a basic ability of Arabic reading and understanding seems sufficient.

\section{Critical Characteristic of Ornamental Inscriptions in Mosques}

Generally, there is an enthusiasm in people to be involved in their built environment. Hence, questioning their preferences and priorities would assist designers to build the user-preferred surroundings. The issue arises for sacred buildings since the users prefer to enter to a homogeneous building rather than to a place which has no connection to their religious beliefs.

\subsection{The Aesthetic Value}

People's perceptions including visual and conceptual abilities may affect their environmental assessments (Ghomeshi \& Jusan, 2013). Ghomeshi and his colleague claimed that nowadays, the aesthetical values in sacred building decorations are an independent field of research and it should be divided from other aspects of architecture. They also added that beauty and preference has a direct relationship in architecture. It means that the time for simple and unadorned structures is past and the public currently appreciate buildings with aesthetical value and decorations. Aesthetical value in sacred building embellishments focuses on appreciation of the religion and how it stimulates our spiritual feelings. The statement is supported by Raeisian (Raeisian, 2013a) as he stated that architectural aesthetics obtains meaning through the intersection between physical qualities of mankind environment as the objective mark and culture and religion as the subjective targets. The mosques are not excluded from this rule. Mosques are obligated to have ornamentations related to the Muslims religious needs and meet the aesthetic requirements of the public. Calligraphy woodcarving ornamentation can fulfil all Malaysian Muslims aesthetic requirements in mosques.

\subsection{The Importance of Function}

There are two common opinions on the function of calligraphic woodcarving decorations among Islamic scholars and users of mosques. The first viewpoint is that the calligraphic woodcarving decorations in mosques are implemented to adorn the sacred structure. They claim that calligraphic woodcarving ornamentation in sacred places carry there is no any other meaning except for beautification values (Ahn, 2007). Conversely, another point of view asserts that calligraphic decorations are applied to convey significant religious messages to the users (Osborn, 2009). This group of scholars believe that the inscriptions are sacred and must be respected more than other types of decorative elements as they display

Public Perception on Calligraphic Woodcarving Ornamentations of Mosques; a Comparison between East Coast and Southwest of Peninsula 
the holy words of God or His messengers. These two different lookouts will be investigated in the current research paper.

\subsection{The Location of Inscriptions}

In Islamic point of view, a mosque is defined as a place where the congregations can perform their prayers and religious activities (Raeisian, 2013b). He also stated that, as the Muslim began to construct the mosques and when the number of mosques increased, the mosque architectural interior elements started to develop. The Muslims began to develop their sacred prostration place. From the prophet's mosque, which had a very simple architecture, today's mosques are considered as real monuments. Over time, architects attached several new components to mosques including arcades and porticos, courtyards, a Mihrab wall, the niche in the Qiblah wall, the fountains for ritual ablution and the minarets that function as a tower to call Muslims for prayers five times a day (Osborn, 2009). However, this study selects five locations of mosques' interior that designers prefer as locations to display decorative inscriptions. Windows, entrances, side walls, Mimbar (pulpit) and Mihrab wall can be considered as the most common location for calligraphic woodcarving ornamentations.

\section{Methodology}

In social science studies, statistical analysis functions like the core of the research. Since finding scientific theories that are identical to reality in the social areas is a challenge, obtaining adequate participants and conducting suitable statistical analysis may train researchers to generate valid and reliable theories. Quantitative method can be regarded as a valid approach for collecting data in social science studies. The questionnaire survey is approved by many scholars as a suitable technique to obtain required information from an extensive population particularly when the subject of public perception is mentioned (Bryman, 2012). In the current study, feedbacks from users of mosques as respondents of the questionnaire survey are collected. The participants are residence of two regions of Peninsular Malaysia, the Southwest and East Coast. The generation of questionnaire survey's content was based on the objective of the study and reviewing the existent literatures. A pilot study was carried out before conducting the actual survey. A technique of test-retest of questionnaire was also done to approve the validity and reliability. It must be noted that the questionnaire was translated to Bahasa Malaysia as the official Malaysian language to be clear and understandable for all respondents of different ages.

The questionnaires were distributed in eight mosques. The researcher selected five mosques in Southwest of Malaysia included Masjid Kampung Kling and Masjid Al Azim in Melaka; Masjid Abu Bakar Sediq and Masjid Sultan Alauddin in Selangor and Masjid Negeri Sembilan in Seremban, Negeri Sembilan. While three mosques also selected from East Coast region of Malaysia namely, Masjid Abidin, Masjid al-Jamhuriah and Masjid Kampung Tasek located in Terengganu. The mentioned mosques were chosen due to the existence of woodcarving calligraphic ornamentations in the mosques.

The sample size of population was selected based on Creswell (2009). To have more accurate results, researchers always wish to test the hypotheses and interpret the outcomes from a wide sample size rather than a minor group of respondents. As Creswell claimed, a sample size of 350 to 400 is acceptable to attain a confidence level of $95 \%$, along with a confidence interval of [ $p=0.05]$, for a population between 1000 to 1500 people (Creswell, 2009). Consequently, 420 questionnaires were randomly distributed among the worshipers in selected mosques. 408 questionnaires out of 420 questionnaires were returned back and completed. The answers were coded and input into SPSS (version 19) software for data analysis process. 
The survey was conducted in May 2013 and ended in July 2013. All the mentioned mosques have a similar trait, which is the application of calligraphic woodcarving ornamentations inside their prayer halls. The decorative inscriptions are mostly displayed on the façade of walls, above windows and entrances, mimbar and mihrab walls.

\subsection{Statistical Approach and Variables Comparison}

As mentioned, two distinguished zones of Peninsular Malaysia were selected. Mann-Whitney test was conducted to compare the opinions of participants who live in these two areas of Malaysia. The items were measured to find out the potential differences between the respondents' opinion in the mentioned two zones. The Mann-Whitney U-Test is a statistical analysis, which can be run by comparing the means. The dependent variables in the current study must be split into two separate variables embracing East Coast $(\mathrm{N}=204)$ and Southwest $(\mathrm{N}=204)$ of Peninsular Malaysia. The test compared the mean of inquired items as independent variables into two split zones of Malaysia as dependent variables. Unlike the T-test, the Mann-Whitney U-test is a non-parametric test since the test does not assume any properties respecting the distribution of the variables which is known as normality in the analysis or using the ordinal scale. In other words, the non-parametric test can be used when the assumptions of a parametric test are violated.

\section{Results}

\subsection{The Ability of Reading and Understanding Quranic Verses}

Mann Whitney U test was conducted to gauge the respondents' ability to read and understand the Arabic words and Quranic verses. Table 1 shows that the mean ranks of participants who live in East Coast of Peninsular Malaysia were higher than Southwest respondents in terms of both evaluated variables. The UTest revealed that there was no significant difference between two areas about the reading Arabic words and it means that participants in both selected areas were able to read Arabic word in almost similar level. However, the level of understanding the meaning of Quranic verses among respondents who live in East Coast was significantly higher than respondents who were in Southwest of Malaysia (Mann-Whitney $\mathrm{U}=$ $18248, \mathrm{~N} 1=\mathrm{N} 2=204, \mathrm{P}=0.02$ ). Figure 3 displays the mean ranks of two assessed variables as a line chart to make the differences easier to understand.

Table 1 U-test regarding to ability of reading and understanding Arabic inscriptions

\begin{tabular}{lcc}
\hline U-Test & Reading Arabic words & Understanding verses \\
\hline Southwest & 202.01 & 191.95 \\
East Coast & 206.99 & 217.05 \\
Mean Difference & -4.98 & -25.1 \\
Mann-Whitney U & 20301 & 18248 \\
Asymp. Sig. (2-tailed) & 0.652 & $0.02^{*}$ \\
\hline
\end{tabular}




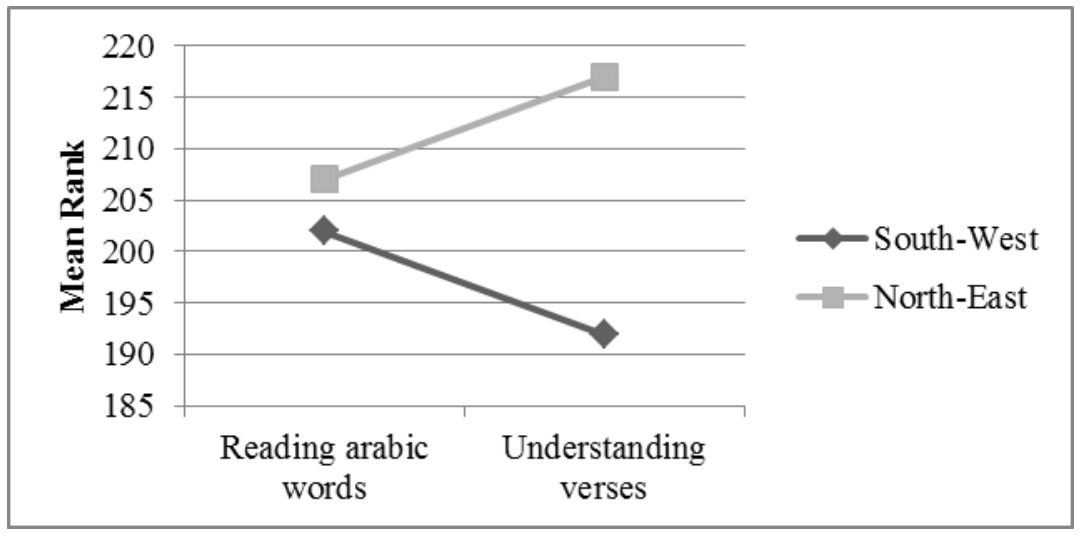

Fig. 3 Comparison about the ability of reading and understanding Arabic language between respondents of Southwest and East Coast

\subsection{The Function of Calligraphic Woodcarving in Mosques}

The U-test revealed that, although there were some differences between the perception of respondents in Southwest and East Coast of Peninsular Malaysia regarding to their opinions on the function of calligraphy wood carving in mosques, Table 2 shows that the significant level was only found in the idea that calligraphy wood carvings function as a way to remind Muslims to pray to Allah (MannWhitney $\mathrm{U}=18459, \mathrm{~N} 1=\mathrm{N} 2=204, \mathrm{P}<0.028$ ). The mean ranks shown in Table 2 prove that the users of mosques who live in East Coast of Peninsular Malaysia think about the function of calligraphy woodcarving in opposite way when compared with the respondents in the Southwest.

Table 2 Respondents' perceptions regarding the function of inscription in mosques

\begin{tabular}{lcc}
\hline U-Test & Decorative element & To praise Allah \\
\hline Southwest & 214.34 & 192.99 \\
East Coast & 194.66 & 216.01 \\
Mean Difference & 19.68 & -23.02 \\
Mann-Whitney U & 18801 & 18459 \\
Asymp. Sig. (2-tailed) & 0.079 & $0.028^{*}$ \\
\hline
\end{tabular}

The line chart as shown in Figure 4 demonstrates the differences of two groups of respondents, who were inquired about the function of Arabic inscriptions in the mosque. In terms of the perspective that calligraphy woodcarving can only be the decorative elements in mosques, the Southwest respondents showed the higher mean rank $(M R=214.34)$ than users in East Coast $(M R=194.66)$ of Peninsular Malaysia. Even though there was a difference between groups of respondents, the difference was not in the level of being significant $(\mathrm{P}>0.05)$. 


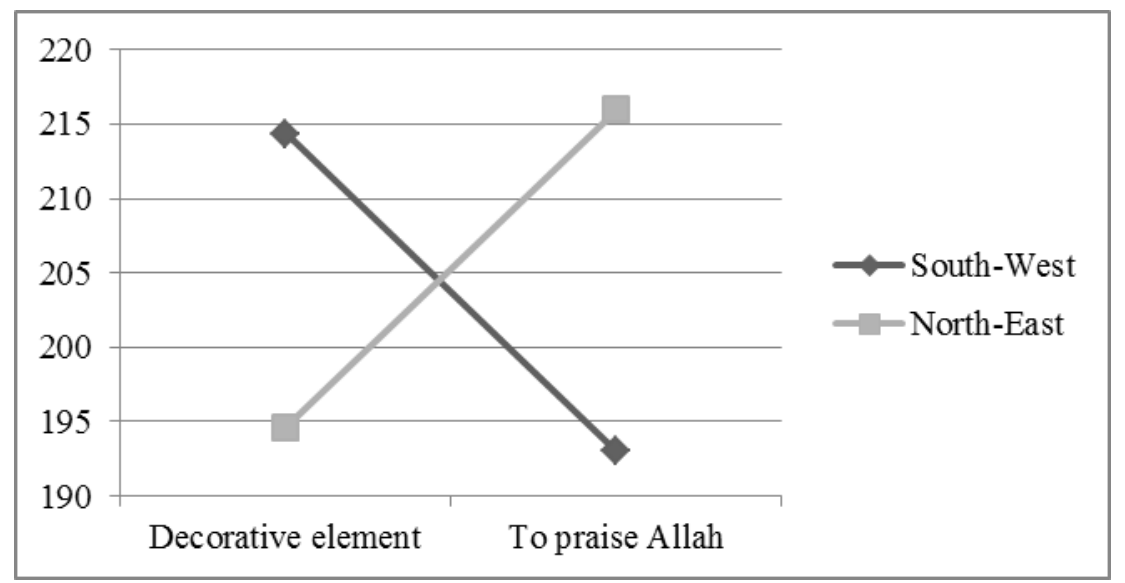

Fig. 4 Comparison about the perception of function between respondents of Southwest and East Coast

\subsection{The Location}

Among the five selected locations of calligraphy woodcarving ornamentation in Malaysian mosques, only windows showed a significant difference between two groups of study (Mann-Whitney $\mathrm{U}=$ $18316.5, \mathrm{~N} 1=\mathrm{N} 2=204, \mathrm{P}<0.026$ ). The mean rank showed that users of Southwest had a higher opinion than the East Coast respondents about the windows as an ideal place for calligraphy wood carving.

Table 3 Respondents' perceptions regarding the location of inscription in mosques

\begin{tabular}{lccccc}
\hline U-Test & Entrance & Windows & $\begin{array}{c}\text { Side } \\
\text { walls }\end{array}$ & Mimbar & $\begin{array}{c}\text { Mihrab } \\
\text { wall }\end{array}$ \\
\hline Southwest & 204.51 & 216.71 & 206.8 & 200.14 & 198.46 \\
East Coast & 204.49 & 192.29 & 202.2 & 208.86 & 210.54 \\
Mean Difference & 0.02 & 24.42 & 4.6 & -8.72 & -12.08 \\
Mann-Whitney U & 20805 & 18316.5 & 20338 & 19919.5 & 19576 \\
Asymp. Sig. (2- & 0.998 & $0.026^{*}$ & 0.671 & 0.397 & 0.253 \\
tailed) & & & & & \\
\hline
\end{tabular}

Interestingly, the test did not find any significant differences between the two evaluated groups on their perception of other common inscription places in the mosques' interior except for windows. Figure 5 displays the differences as a line chart. As it can be seen, the perception of respondents in Southwest and East Coast of peninsular Malaysia were almost similar. 


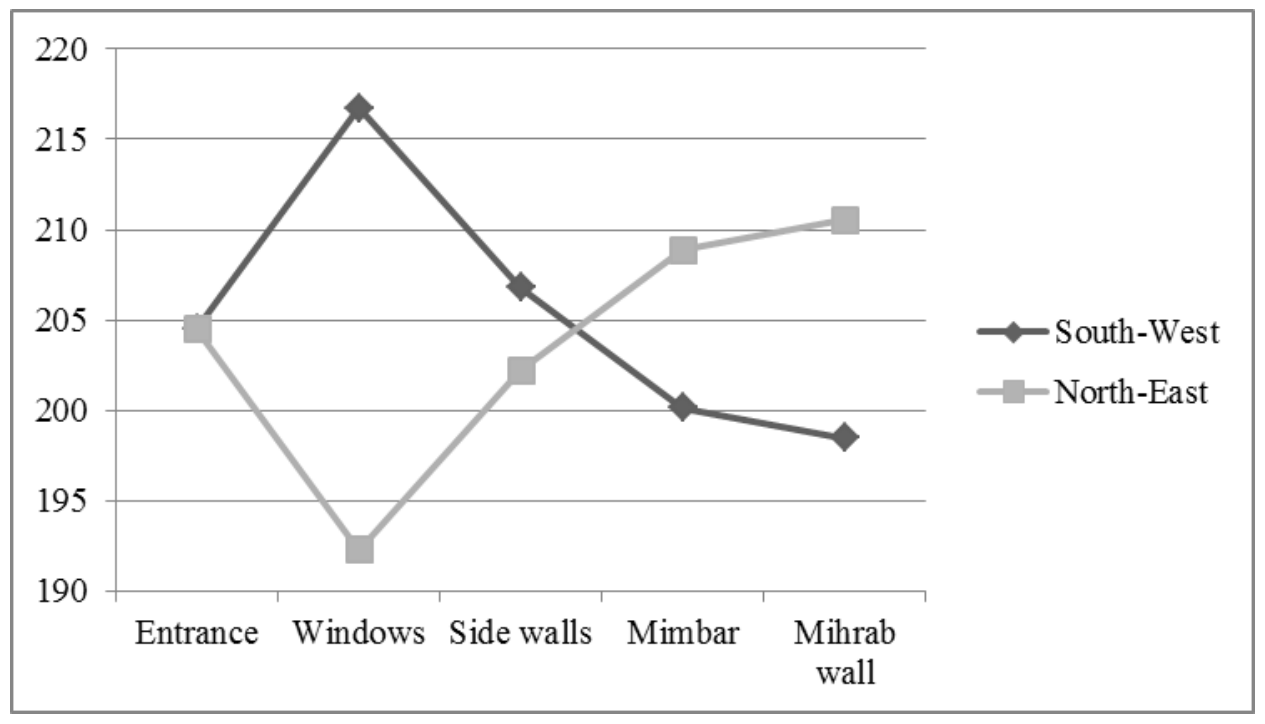

Fig. 5 Comparison about the most suitable location of decorative inscription in mosques between respondents of Southwest and East Coast

\subsection{Readability of Scripts}

The readability level of scripts was evaluated between the respondents of Southwest and East Coast of Peninsular Malaysia through Mann Whitney U-test. Table 4 presents the results of the U-test. The respondents of two groups had similar opinion about Thuluth and Diwani scripts as their Asymp. Sig were greater than 0.05. The mean ranks revealed that users of East Coast mosques found the Thuluth more readable than the people in Southwest. Meanwhile, the feedback about the Diwani script was contrary.

Table 4 Respondents' perceptions regarding the readability of inscription in mosques

\begin{tabular}{llcllc}
\hline U-Test & Thuluth & Kufi & Naskh & Nastaliq & Diwani \\
\hline Southwest & 200.38 & 231 & 189.97 & 185.31 & 214.75 \\
East Coast & 208.62 & 178 & 219.03 & 223.69 & 194.25 \\
Mean Difference & -8.24 & 53 & -29.06 & -38.38 & 20.5 \\
Mann-Whitney U & 19968 & 15402 & 17843 & 16892.5 & 18718 \\
Asymp. Sig. (2-tailed) & 0.467 & $0.0^{* *}$ & $0.006^{*}$ & $0.001^{*}$ & 0.063 \\
\hline
\end{tabular}

Nonetheless, the U-Test proved that there were significant differences between respondents in Southwest and East Coast of Peninsular Malaysia about the readability of some scripts including Kufi (MannWhitney $\mathrm{U}=15402, \mathrm{~N} 1=\mathrm{N} 2=204, \mathrm{P}<0.00), \quad$ Naskh $\quad($ Mann-Whitney $\mathrm{U}=17843, \mathrm{~N} 1=\mathrm{N} 2=$ 204, P<0.006) and Nastaliq (Mann-Whitney $\mathrm{U}=16892.5, \mathrm{~N} 1=\mathrm{N} 2=204, \mathrm{P}<0.001$ ). Although the respondents of Southwest were more comfortable with the legibility of Kufi script rather than East Coast participants, the mean ranks revealed that other two scripts showed opposite answers. Users who live in East Coast were more able than respondents of Southwest in reading Naskh and Nastaliq scripts. Figure 6 displays the differences between two groups of study. 


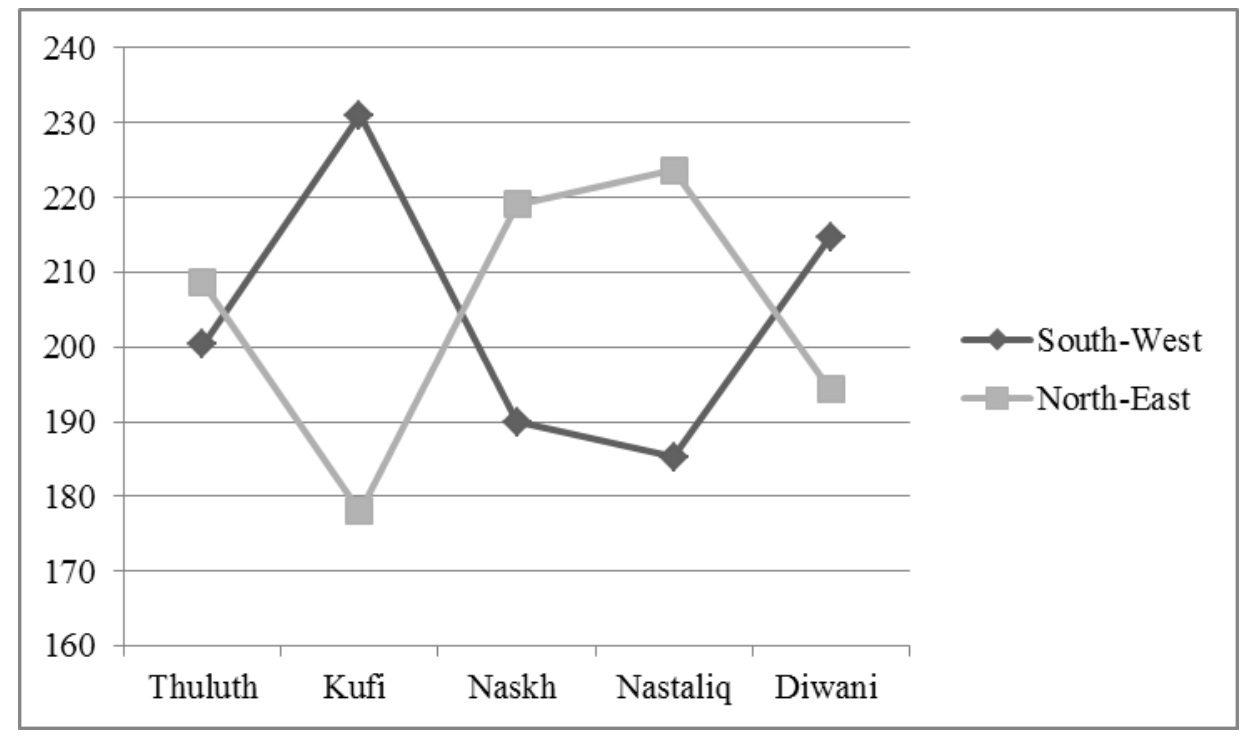

Fig. 6 Comparison about the readability of decorative inscription in mosques between respondents of Southwest and East Coast

\subsection{Beauty of Scripts}

A Mann-Whitney U-test was conducted to answer the research objective that purposed to compare the two groups of participants. In terms of the beauty of scripts, significant differences were found in Thuluth (Mann-Whitney U = 18183, N1 = N2 = 204, P<0.018), Naskh (Mann-Whitney U = 16728, N1 = N2 = 204, P<0.00) and Diwani (Mann-Whitney $\mathrm{U}=17018, \mathrm{~N} 1=\mathrm{N} 2=204, \mathrm{P}<0.001$ ) between participants from Southwest and East Coast of Peninsular Malaysia. Surprisingly, the mean ranks in Table 5 show that respondents from Southwest rated higher points than East Coast participants in terms of the beauty of mentioned scripts.

Table 5 Respondents' perceptions regarding the beauty of inscription in mosques

\begin{tabular}{llllll}
\hline U-Test & Thuluth & Kufi & Naskh & Nastaliq & Diwani \\
\hline Southwest & 217.37 & 209.03 & 224.5 & 202.55 & 223.08 \\
East Coast & 191.63 & 199.97 & 184.5 & 206.45 & 185.92 \\
Mean Difference & 25.74 & 9.06 & 40 & -3.9 & 37.16 \\
Mann-Whitney U & 18183 & 19884.5 & 16728 & 20409.5 & 17018 \\
Asymp. Sig. (2-tailed) & $0.018^{*}$ & 0.393 & $0.0^{* *}$ & 0.726 & $0.001^{*}$ \\
\hline
\end{tabular}

Despite the differences between two evaluated groups about the beauty of Kufi and Nastaliq scripts, the U-Test revealed that the differences were not significant enough as the $\mathrm{p}$-value were recorded higher than 0.05. Figure 7 demonstrates that the Nastaliq was the only script which participants in East Coast considered as more beautiful than Southwest respondents. 


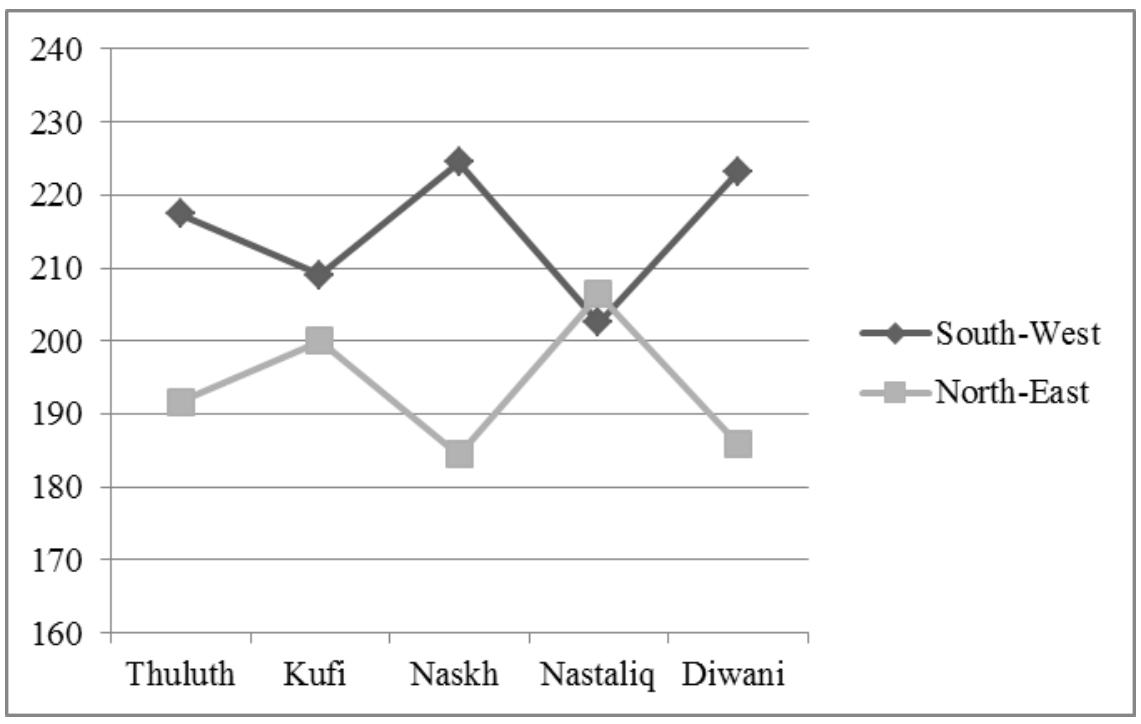

Fig. 7 Comparison about the beauty of ornamental inscription in mosques between respondents of Southwest and East Coast

\subsection{Preference of Scripts}

The results of the U-test in Table 6 indicated that the perceptions of Southwest and East Coast respondents toward the preference of observing Naskh (Mann-Whitney $\mathrm{U}=14284, \mathrm{~N} 1=\mathrm{N} 2=$ 204, P<0.018) and Nastaliq (Mann-Whitney $\mathrm{U}=14100, \mathrm{~N} 1=\mathrm{N} 2=204, \mathrm{P}<0.00$ ) significantly differed at 0.001 levels. In other words, the Southwest respondents perceived the Naskh script to be significantly more attractive when compared with East Coast people, while it was opposite in Nastaliq. However, the existence of statistically significant difference between Southwest and East Coast respondents' perceptions could not be supported for the reminder scripts such as Thuluth, Kufi and Diwani (p-value > $0.05)$.

Table 6 Respondents' perceptions regarding the preference of inscription in mosques

\begin{tabular}{llllll}
\hline U-Test & Thuluth & Kufi & Naskh & Nastaliq & Diwani \\
\hline Southwest & 197.3 & 202.03 & 236.48 & 171.62 & 207.72 \\
East Coast & 211.7 & 206.97 & 172.52 & 237.38 & 201.28 \\
Mean Difference & -14.4 & -4.94 & 63.96 & -65.76 & 6.44 \\
Mann-Whitney U & 19340 & 20304.5 & 14284 & 14100 & 20151.5 \\
Asymp. Sig. (2-tailed) & 0.189 & 0.653 & $0.0^{* *}$ & $0.0^{* *}$ & 0.565 \\
\hline
\end{tabular}

Figure 8 gives a good illustration about the mean differences of the variables between Southwest and East Coast respondents' perceptions. The mean rank stated that participants in East Coast were more eager than Southwest mosque's users to see Thuluth, Kufi and Naskh scripts as the calligraphy woodcarving ornamentation scripts. Nonetheless, the condition for Nastaliq and Diwani was contrary as the mean rank of Southwest respondents was higher than participants in East Coast of peninsular Malaysia. 


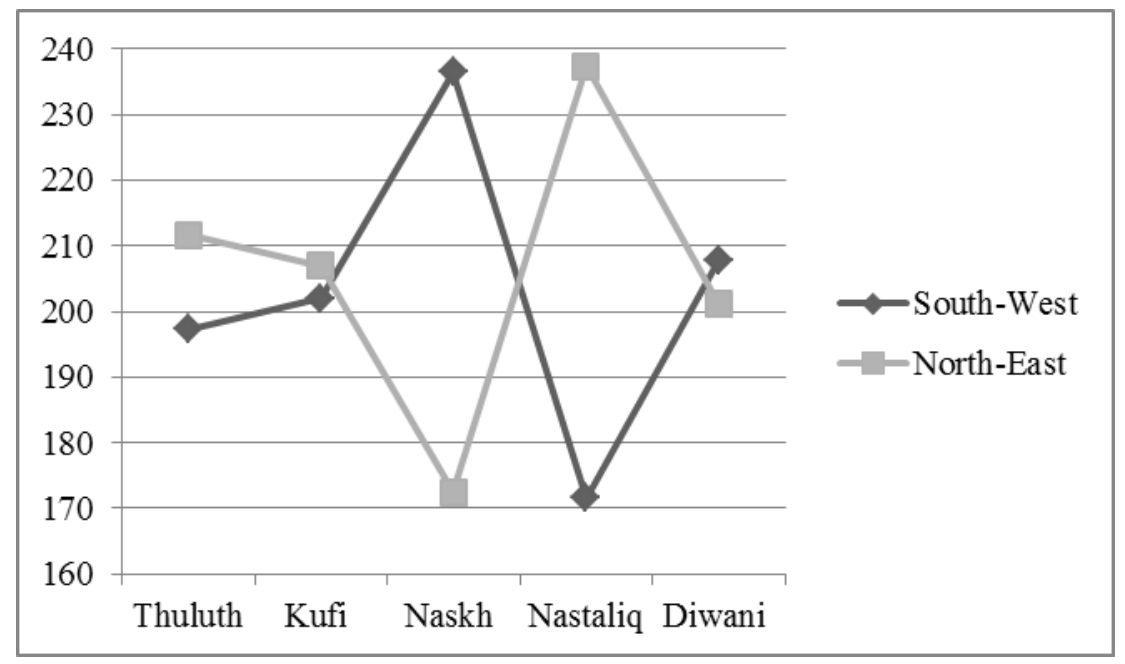

Fig. 8 Comparison about the preference of ornamental inscription in mosques between respondents of Southwest and East Coast

\section{Discussion}

The current paper focuses on the evaluation of mosques' users about the calligraphic woodcarving ornamentation in the eight well-known mosques of Peninsular Malaysia and examined several items including the ability to read and understand Arabic inscriptions, the function of calligraphic ornamentation inside the prayer hall of the mosques, the most suitable location, the level of legibility, beauty, and finally the preference of ornamental inscriptions.

The current study is carried out through exploratory quantitative approach as there is a lack of past studies on calligraphic wood carving decorations in mosques and its relationship to public perception. The outcome of study proved the new contribution of the research, whilst the results are also useful for the interior designers and architectures to design more appropriate ornamentations in different regions. Moreover, the findings are valuable for mosque users who frequently use mosques for Friday-daily prayer and other religious activities. Woodcarving is regarded as one of the Malaysian Heritages, and the users appreciated the application of this artefact in Malaysian mosques. The calligraphic woodcarving ornamentations cover both Islamic and cultural values if they are applied in the suitable location and the needs of users are met.

It is assumed that public has the right to observe their opinions about the decoration of mosques as the one who use the building daily. Although designers would also find out about the preferences of the users, the viewpoints of people in different regions are varied. Therefore, the current research settles the feedbacks of the public on the calligraphic woodcarving ornamentations in terms of the function, suitable location, legibility, aesthetic and preference of decorative inscriptions.

Shahedi et al. (2012) noted that the public perception is observed to be more meaningful and measurable through their knowledge about ornamental architectural elements. Additionally, there are several other factors such as religion, culture and moral interests connected to the public perception despite the fact that the participants answered differently to the interview questions that proved the multiplicity of viewpoints between two measured regions. Yet, variety in opinions, different environment and specialized knowledge between the people in Southwest and East Coast of Malaysia about calligraphic ornamentations were the main reasons of differences in opinions. 
The results of U-test about the ability to read and understand Arabic language were surprising. The people who live in East Coast of Peninsular Malaysia are more able to read and comprehend Arabic than respondents in the Southwest. Although the ability of reading the Arabic scripts in both groups is almost in a same level, the East Coast people are better with a wide difference in understanding Arabic than people from Southwest. The probable reason could be the unity of Malay people in the North East states such as Terengganu. The multi-cultural phenomenon in Southwest regions of Malaysia affects encourage of Malay locals in learning Arabic.

According to statistical results, although the majority of respondents claimed that calligraphy ornamentation comprises both function in mosques, the respondents' opinions in North East and Southwest of Peninsular Malaysia were different. The people in Southwest observed woodcarving inscriptions more as a decorative element. On the contrary, respondents of East Coast believed that calligraphic woodcarving ornamentations as a way to remind them of Allah and to pray to Allah. It seems that there is a direct relationship between the ability of comprehending Arabic language and the determination of its functions. Since people in Southwest could not understand Arabic language properly, consequently, they perceived it as decorative element.

Further, it proves that religious function was taken into consideration rather than the aesthetic value. Their Islamic interest and background influenced the respondents' opinions. It also can be noted that the interior ambience of mosques effected the respondents' perceptions about the function of calligraphic woodcarving ornamentations although they are mainly applied as embellishments in the prayer hall rather than to be read and used as a tool to connect the Divinity and his worshipers.

The results of inferential analysis also displayed that North East and Southwest respondents looked at the calligraphic woodcarving ornamentations as decorative elements in a similar degree of interest. However, the differences of North East and Southwest participants about the decorative inscriptions as a way to praise Allah were significant. Perhaps, the disparity is developed from the multi-cultural society that Southwest is encountered. While the religious schools (sekolah ugama) in the East Coast play an important role in increasing peoples' Islamic knowledge.

The suitability of location for calligraphic woodcarving ornamentations was assessed from two groups of study. According to the results of questionnaire survey, the window is a debated place for displaying decorative inscriptions since there were differences between the opinions of respondents in Southwest and East Coast of Malaysia. On the hand, the entrance of prayer hall had the minimum diversity of opinion. Although, the respondents from the East Coast prefered mihrab wall as their first choice for ornamental inscriptions, the respondents from the Southwest selected windows of mosques as their first option.

The Thuluth script was the only writing style found in the ornamentation elements of all eight observed mosques either in East Coast or Southwest of Peninsula Malaysia. When the respondents are divided into East Coast and Southwest groups, the results are more interesting. It is revealed that the legibility and preference of Thuluth are almost similar for both groups of study. Meanwhile, in terms of aesthetic, Southwest respondents observed this writing style to be more beautiful than respondents from East Coast. It can be noted that Thuluth is a very common scripts among the decorative scripts in Malaysia, thus it is logical to see similar level of popularity throughout Malaysia. It seems possible that these results are due to the popularity of Thuluth as the main decorative script in Malaysian mosques. However, the maximum level of readability was found in Naskh script through the opinion of East Coast participants. Conversely, the respondents from Southwest observed Kufi as the most readable decorative scripts.

Furthermore, this study also compared the assessments of East Coast and Southwest respondents about the aesthetic value of calligraphic ornamentations. Interestingly, the results proved that the religious viewpoints of respondents in East Coast have influence on their concerns about mosque ornamentations as well. Although the East Coast respondents showed higher level of interest and were more pleased by 
Nastaliq scripts than people in Southwest, they also thought that the aesthetic value of calligraphic woodcarving decoration is a logical reason why it must be a requirement for the prayer hall of mosques. The comparison indicated that respondents in the East Coast became more interested to read and understand the inscriptions more than respondents in Southwest when they found them beautiful.

Naskh writing style was the second most used script observed in the selected mosques even though it is mostly used for writing of books. However, it observed that this style was used in three mosques out of eight. The high score of readability, average score of aesthetic and low score of desirability of Naskh script showed that despite the appropriateness of legibility, mosque users did not prefer to observe it in mosques as a decorative inscription. Moreover, it was found that respondents from East Coast were more enthusiastic in Naskh writing style than Southwest respondents. The probable reason could be the easiness of readability as Naskh is used in writing the religious books. The final outcome expresses that Naskh is not a proper writing style for decorative woodcarving inscriptions in mosque, despite it being the most relevant for writing the Quran.

\section{Conclusion}

The current paper answers the connection between users' perception and calligraphic woodcarving ornamentations in mosques. The two important regions of Peninsula Malaysia were investigated and the results were interesting. This study evaluated a subjective skill which is ability of reading and understanding Arabic script and the objective items such as the function of calligraphy in the prayer hall of mosques, the most appropriate location of decorative inscriptions, the aesthetical and legibility aspects, the preferred writing styles. The analyses are revealed the knowledge and preference of prayers regards to their personal evaluation.

It can be concluded that the sensations of humans, particularly visual determination, may affect the environmental perception and evaluation. They stated that aesthetical standards in sacred ornamentations are nowadays an independent field of study and it must be segregated from other parts of architectural aspects. Aesthetical standards in architectural ornamentations focus on the appreciation of the environment and how it inspirations our thoughts in a satisfying way. Artistic inventions derive from the mutual relationship between people's capability and the factors such as culture and religion.

\section{References}

Agha, A. (2015). Religious Discourse in Tablighi Jama'at: A Challenge to Female Sexuality?. International Journal of Multicultural and Multireligious Understanding, 2(3), 1-16.

Ahmad, Maheram, \& Resad, Izziah Suryani Mat. (2015). Use of Arabic Language in Terengganu in the Early 20th Century. Mediterranean Journal of Social Sciences, 5(29), 49.

Ahn, You Kyong. (2007). Adaptive reuse of abandoned historic churches: Building type and public perception: Texas A\&M University.

Blair, Sheila S. (2006). Islamic calligraphy: Edinburgh University Press Edinburgh.

Bryman, Alan. (2012). Social research methods: Oxford university press.

Creswell, John. (2009). Research design: Qualitative, quantitative, and mixed methods approaches: SAGE Publications, Incorporated. 
Etikan, Serna. (2008). The use of the Kufic script, an element of Islamic ornament in Turkish Rug Art. Social Sci, 3(2), 104-112.

George, Alain. (2010). The Rise of Islamic Calligraphy. Published by University of Edinburgh: Al Saqi.

Ghomeshi, Mohammad, \& Jusan, Mahmud Mohd. (2013). Investigating Different Aesthetic Preferences Between Architects And Non-Architects In Residential Façade Designs. Indoor and Built Environment, 22(6), 952-964.

Henderson, Joan C. (2003). Managing tourism and Islam in peninsular Malaysia. Tourism Management, 24(4), 447-456.

Hillenbrand, Robert. (1999). Islamic art and architecture: Thames and Hudson London.

Kamarudin, Zumahiran Binti, \& Said, Ismail. (2009). Principal Orders in the Composition of Woodcarvings and its Layouts in Kelantan and Terengganu Traditional Houses (Vol. 3, pp. 12-23): UTM journal.

Kostof, Spiro. (1995). A history of architecture: settings and rituals. New York: Oxford.

Mazumdar, Shampa, \& Mazumdar, Sanjoy. (2004). Religion and place attachment: A study of sacred places. Journal of environmental psychology, 24(3), 385-397.

Najafi, Mina, \& Kamal, Mustafa. (2012). INVESTIGATION OF USERS'ATTACHMENT TO MALAYSIAN MOSQUES. ALAM CIPTA, International Journal of Sustainable Tropical Design Research and Practice, 5(2), 65-76.

Nasir, Abdul Halim. (1987). Traditional Malay wood carving. Kuala Lumpur, Malaysia: Dewan Bahasa dan Pustaka, Ministry of Education of Malaysia.

Osborn, JR. (2009). Narratives of Arabic Script: Calligraphic Design and Modern Spaces. Design and Culture, 1(3), 289-306.

Raeisian, Gholamreza. (2013a). The Role of Mosques in Urban Development. Journal of Civil Engineering and Urbanism, 3, 20-29.

Raeisian, Gholamreza. (2013b). The Role of Mosques in Urban Development. Journal of Civil Engineering and Urbanism, 3.

Saberi, A., Endut, E. H., Ahmad, S. S., Motamedi, S., \& Kariminia, S. (2015). Users' Perceptions of Different Genders about Calligraphic Woodcarving Ornamentations in Malaysian Mosques. Architecture Research, 5(2), 52-60.

Shahedi, Bahram, Keumala, Nila, \& Yaacob, Naziaty Mohd. (2012). Perception of Aesthetic Design Approach: Safavid Architecture. Journal of Design and Built Environment.

Suleiman, Yasir. (1999). The Arabic Language. Islam \& Christian Muslim Relations, 10(1), 102. Turgut, Özden Pektaş. (2014). Calligraphic Forms in Contemporary Typographic Design. Procedia Social and Behavioral Sciences, 122(0), 40-45. 
Utaberta, Nangkula, Sojak, SDM, Surat, M, Che-Ani, AI, \& Tahir, MM. (2012). Typological study of traditional mosque ornamentation in Malaysia: Prospect of traditional ornament in urban mosque. World Academy of Science, Engineering and Technology, 67, 624-631.

\section{Copyrights}

Copyright for this article is retained by the author (s), with first publication rights granted to the journal.

This is an open-access article distributed under the terms and conditions of the Creative Commons Attribution license (http://creativecommons.org/licenses/by/4.0/). 